\title{
IDENTIFICAÇÃO E AVALIAÇÃO DOS TEORES DE METAIS TÓXICOS EM BATONS
}

\section{IDENTIFICATION AND EVALUATION OF TOXIC METALS IN LIPSTICK}

\author{
Bruna Rosângela Ribeiro Gonçalves ${ }^{1}$; Larissa de Jesus Rodrigues ${ }^{1}$; Daniel \\ Ângelo Macena ${ }^{1}$; Maíra Rodrigues Uliana ${ }^{1}$; Vinícius Marques Gomes ${ }^{1}$. \\ ${ }^{1}$ Universidade do Oeste Paulista - UNOESTE, Curso de Química Bacharelado, \\ Presidente Prudente, SP. \\ e-mail: viniciusmarques@unoeste.br
}

RESUMO - Consumidores cada vez mais exigentes têm feito com que empresas do ramo de cosméticos invistam em produtos e pesquisas, visando melhorar a qualidade dos produtos, valorizando sempre à saúde do consumidor e a sustentabilidade. Alguns metais são essenciais para o bom desenvolvimento dos seres vivos, porém existem outros que são prejudiciais à saúde. De todos os metais apenas 30 são tóxicos, entre esses metais estão o chumbo, o cádmio e o crômio. Esses metais estão presentes nos pigmentos utilizados na fabricação dos batons e a legislação estabelece limites de segurança para a presença desses metais em cosméticos, pois o risco de contaminação está ligado à concentração e exposição ao mesmo. Por este motivo a análise de metais potencialmente tóxicos em batons se faz necessária, quantificando e comparando com os teores apresentados não só pelas empresas, mas também pela legislação vigente. Desta forma este estudo teve como objetivo quantificar os teores de chumbo, cádmio e crômio em batons de diferentes marcas, utilizando método de digestão ácida e determinação por espectrometria de absorção atômica. Pelos resultados, foi possível observar a presença de altos teores de cádmio em todas as marcas analisadas, sendo as maiores concentrações encontradas nas tonalidades mais escuras.

Palavras-chave: toxicidade; chumbo; cádmio; crômio.

ABSTRACT - More and more demanding consumers have made cosmetic companies invest in products and research aiming at improve product quality and enhance consumer health and sustainability. Some metals are essential for the good development of beings, but there are others that are harmful to health. Of all metals only 30 are toxic, and lead, cadmium and chromium belong to this group. These metals are present in the pigments used in the manufacture of lipsticks. The legislation establishes safety limits for the presence of these metals in cosmetics, since the risk of contamination is linked to their concentration and exposure. For this reason the analysis of potentially toxic metals in lipsticks is necessary, quantifying and comparing to the contents presented not only by the companies, but also by the current legislation. Thus, this study aimed to quantify the levels of lead, cadmium and chromium in lipsticks of different brands, using acid digestion method and determination by atomic absorption spectrometry. From the results, it was possible to observe the presence of high levels of cadmium in all the analyzed brands and the highest concentrations were found in the darker shades.

Keywords: toxicity; lead; cadmium; chromium. 


\section{INTRODUÇÃO}

A indústria de cosméticos no Brasil, em 2014, teve uma movimentação financeira de cerca de US\$ 40 bilhões, atrás apenas dos Estados Unidos e Japão. Os valores são referentes às vendas no mercado interno e reflexo do maior interesse da população a estes produtos (Augusto e Filho, 2014).

Uns dos grandes atrativos no mercado dos cosméticos estão na combinação de cores, que nada mais são do que pigmentos inorgânicos em sua formulação, especialmente em sombras e batons (FRAGA \& ATZ, 2008). Segundo Atz (2008), os corantes e pigmentos inorgânicos são os responsáveis pela coloração desejada, pela maleabilidade, pela fixação e durabilidade do cosmético labial. Os principais componentes desses pigmentos inorgânicos e corantes são elementos metálicos, que nem sempre apresentam a pureza adequada e acabam por incluir elementos metálicos indesejados, tais como mercúrio $(\mathrm{Hg})$, chumbo $(\mathrm{Pb})$, níquel $(\mathrm{Ni})$, entre outros.

Os cosméticos labiais são parte de um segmento da indústria de higiene pessoal, perfumes e cosméticos (BATISTA, 2017). Este tipo específico de cosmético possui diversas funções como realçar ou dar cor aos lábios, proteger de queimaduras solares, lubrificar os lábios ou disfarçar imperfeições indesejadas. Existem diversos tipos de cosméticos labiais como os batons, delineadores de boca, cremes, hidratantes e brilhos labiais (AUGUSTO E FILHO, 2014).

Segundo Higuchi (2014) alguns cosméticos possuem metais tóxicos em sua composição (cádmio, crômio e chumbo), que causa risco tanto para o ambiente, devido ao descarte inadequado, quanto à saúde do homem. O chumbo em cosméticos desperta atenção devido à alta toxicidade por fonte de exposição, comprometendo o sistema renal e nervoso central, além de perda de memória. O chumbo é bioacumulativo e as vias de introdução são por inalação, absorção pela pele e ingestão (ATZ, 2008).

O sistema nervoso de um adulto, por exemplo, pode ser afetado em baixas concentrações de chumbo em média de $40 \mu \mathrm{g} . \mathrm{L}^{-}$ 1 , enquanto que na fase de desenvolvimento da criança, a concentração significativa para afetar o sistema nervoso é menor que $10 \mu \mathrm{g} . \mathrm{L}^{-1}$ (MOREIRA \& MOREIRA, 2015). Um estudo realizado por
Soares (2012) foram analisados 22 amostras de batons de diferentes marcas e foi detectada a presença de chumbo em 21 amostras do total analisadas e obteve variação de 0,27 a 4,45 $\mu \mathrm{g} \cdot \mathrm{g}$ 1 .

De acordo com Chorilli et al. (2007) na legislação brasileira não se exige testes de toxicidade para o registro de produtos cosméticos. De acordo com a Resolução 79/00, Anexo XXI e suas atualizações, o que existe é apenas um termo de responsabilidade que a empresa assina, onde a mesma declara possuir dados comprobatórios que atestam a eficácia e segurança de seus produtos.

Este trabalho foi realizado com o intuito de investigar os teores de metais tóxicos (chumbo, crômio e cádmio) através da técnica de Espectrofotometria de Absorção Atômica em chama (FAAS) presentes em batons das marcas líderes de mercado e verificar se tais concentrações estão de acordo com o especificado no rótulo do produto e se estão dentro dos valores máximos permitidos pela legislação.

\section{MÉTODO}

As análises foram realizadas nos laboratórios de Química, localizados no Bloco Q, da Universidade do Oeste Paulista - UNOESTE de Presidente Prudente, estado de São Paulo. As amostras foram adquiridas em estabelecimentos brasileiros, físicos, especializados na venda de cosméticos. Em princípio foram selecionadas três marcas de batons, de cores diferentes (um grupo de cor clara e outro de cor escura), que foram submetidas às análises de caráter qualitativo e quantitativo.

Os critérios levados em consideração na pesquisa foram:

A - Preço - produtos de baixo e elevados valores.

B - Coloração - sendo de tons claros (nude) a tons mais fortes (roxo).

C - Tipo de produto - batom em bastão, o mais utilizado por mulheres.

As digestões foram realizadas em triplicatas em bloco digestor a $120^{\circ} \mathrm{C}$. Para cada amostra, pesou-se $2 \mathrm{~g}$ de batom em tubos de borosilicato, adicionando $20 \mathrm{~mL}$ de $\mathrm{HNO}_{3}$ concentrado P.A. e deixando em repouso por 2 horas (TREVIZAM et al., 2010).

Seguiu-se ao aquecimento a $120{ }^{\circ} \mathrm{C}$ por 2 horas. Após o resfriamento, adicionou-se $4 \mathrm{~mL}$ de $\mathrm{H}_{2} \mathrm{O}_{2} 30 \% \mathrm{v} / \mathrm{v}$, permanecendo em aquecimento 
por mais 1 horas. Após breve resfriamento, os extratos obtidos foram filtrados, transferidos para balões volumétricos e completados com água ultrapura. Em seguida, foram armazenados e refrigerados à temperatura de $4{ }^{\circ} \mathrm{C}$ até a realização das análises (BATISTA, 2017).

Para a determinação dos teores de $\mathrm{Pb}, \mathrm{Cd}$ e $\mathrm{Cr}$ foi utilizado o Espectrômetro de Absorção Atômica de chama (FAAS) equipado com uma lâmpada de deutério como corretor de fundo, lâmpadas de cátodo-oco contendo o analito e gás acetileno como combustível para a chama (ZINI et al., 2009; BATISTA, 2017).

O delineamento experimental foi inteiramente casualizado, em esquema fatorial 3 x 2 ( 3 marcas $\times 2$ cores/tonalidades), com quatro repetições, onde cada repetição foi representada por uma embalagem (todas do mesmo lote), totalizando 24 amostras (TABELA 1).

Tabela 1. Delineamento experimental da pesquisa.

\begin{tabular}{l|c|c}
\hline \multirow{2}{*}{ Marcas } & \multicolumn{2}{|c}{ Cores/Tonalidades } \\
\cline { 2 - 3 } & Claro & Escuro \\
\hline Marca 1 & $\mathrm{T}_{1}$ & $\mathrm{~T}_{2}$ \\
\hline Marca 2 & $\mathrm{T}_{1}$ & $\mathrm{~T}_{2}$ \\
\hline Marca 3 & $\mathrm{T}_{1}$ & $\mathrm{~T}_{2}$ \\
\hline Fonte: & Próprio autor. $\mathrm{T}_{1}$-Tratamento \\
Tratamento2. & \multicolumn{2}{|c}{}
\end{tabular}

Os resultados foram tratados por análise de variância (ANOVA), seguida por teste de comparação de médias, e foram expressos em tabelas.

\section{RESULTADOS}

As amostras foram analisadas por espectrometria de absorção atômica com atomização em chama no intuito de identificar a quantidade de metais presentes em cada amostra, verificando em qual marca e tonalidade apresentava concentração de metal tóxico significativa. Os resultados estão apresentados em tabelas e cálculos estatísticos para verificar se houve ou não variação entre as marcas e tonalidades.
TABELA 2. Teores de chumbo, cádmio e crômio em diferentes marcas e cores de batom.

\begin{tabular}{c|c|c|c}
\hline Marca & Chumbo & Cádmio & Crômio \\
\hline $\mathbf{1}$ & $0,05 \mathrm{a}$ & $0,11 \mathrm{~b}$ & 0,43 \\
\hline $\mathbf{2}$ & $0,08 \mathrm{a}$ & $0,11 \mathrm{~b}$ & 0,25 \\
\hline $\mathbf{3}$ & $0,06 \mathrm{a}$ & $0,17 \mathrm{a}$ & 0,33 \\
\hline $\mathbf{F}$ & $3,48 \mathrm{~ns}$ & $34,99^{* *}$ & $1,31 \mathrm{~ns}$ \\
\hline Cor & Chumbo & Cádmio & Crômio \\
\hline Nude & $0,05 \mathrm{~b}$ & $0,11 \mathrm{~b}$ & $0,36 \mathrm{a}$ \\
\hline Roxo & $0,08 \mathrm{a}$ & $0,15 \mathrm{a}$ & $0,31 \mathrm{a}$ \\
\hline $\mathbf{F}$ & $9,46^{* *}$ & $29,94^{* *}$ & $0,26 \mathrm{~ns}$ \\
\hline $\mathbf{F ~} \mathbf{m}^{*} \mathbf{c}$ & $1,08 \mathrm{~ns}$ & $8,83^{* *}$ & $0,75 \mathrm{~ns}$ \\
\hline C.V. (\%) & 40,56 & 12,01 & 63,49 \\
\hline
\end{tabular}

Fonte: próprio autor.

A TABELA 2 apresenta a análise estatística relacionada às variações da concentração dos teores dos metais nas marcas estudadas, enquanto que a TABELA 3 apresenta os resultados estatísticos.

Tabela 3. Desdobramento da interação entre marca e tonalidade de batom.

\begin{tabular}{ccccc}
\hline Marca & \multicolumn{2}{c}{ Roxo } & \multicolumn{2}{c}{ Nude } \\
\hline $\mathbf{1}$ & 0,14 & bA & 0,09 & bB \\
$\mathbf{2}$ & 0,12 & bA & 0,12 & aA \\
$\mathbf{3}$ & 0,21 & aA & 0,14 & aB \\
\hline
\end{tabular}

Fonte: próprio autor.

A estatística mostra que em relação aos teores de chumbo não houve diferença entre as marcas. No entanto, entre as tonalidades, o roxo apresentou maior teor de chumbo. Para cádmio a marca 3 apresentou maior teor em relação as demais marcas, e entre as tonalidades, o tom roxo apresentou maior valor novamente. Quanto ao crômio, não houve variação significativa entre as marcas e nem entre as tonalidades.

\section{DISCUSSÃO}

Segundo a Agência Nacional de Vigilância Sanitária (ANVISA), o chumbo não é utilizado em batons, podendo apenas aparecer como um contaminante em forma de corantes e pigmentos, visto que possui um limite máximo permitido de até $20 \mathrm{mg} \cdot \mathrm{L}^{-1}$, conforme estabelecido no Decreto 79094/77, art. 49, item III - "g". De acordo com a TABELA 2, nota-se que os teores de chumbo, para todas as marcas e tonalidades, estão abaixo do valor máximo estabelecido pela ANVISA, abaixo de estudos anteriores (ATZ, 2008; SOARES, 2012) e a presença do chumbo não apresenta diferenças 
significativas quando se comparam marcas, porém, entre as tonalidades, o tom roxo obteve valor maior.

Para os teores de cádmio encontrado nas amostras, observa-se uma variação mais significativa quando comparados os valores de concentração entre as marcas, visto que a amostra 3 apresentou concentração relativamente mais elevada em relação as outras. Quanto a tonalidade, o tom roxo novamente obteve um teor maior de cádmio.

Os teores obtidos estão abaixo do valor máximo estabelecido pela ANVISA e abaixo de estudos anteriores (ATZ, 2008).

No entanto, apesar de altamente tóxico, bioacumulativo e podendo causar distúrbios renais e ósseos, hipertensão, doenças do coração e até câncer, o cádmio também não representa perigo a saúde humana quando ingeridos nessas concentrações.

Os teores de crômio, apesar de parecerem altos em relação aos de chumbo e cádmio, não apresentaram diferença significativas quanto à marca e tonalidade segundo os cálculos estatísticos. Os teores obtidos estão abaixo do valor máximo estabelecido pela ANVISA e abaixo de estudos anteriores (ATZ, 2008).

Já de acordo com a TABELA 2 é possível observar que em relação às marcas, o único metal que teve variação significativa foi o cádmio nas marcas 1 e 2 . Quanto à tonalidade, o nude teve uma variação significativa para o chumbo e o cádmio.

\section{CONSIDERAÇÕES FINAIS}

De acordo com os resultados obtidos, é possível concluir que na amostra de menor valor e a tonalidade influenciam no teor de metal presente, visto que a marca de valor mais inferior é que houve maior variância de metal presente, e a tonalidade escura (roxo) detectou um teor maior de chumbo e cádmio.

Apesar da presença desses metais nos batons e de suas concentrações encontradas, em nenhuma das marcas o teor de metal estava acima do permitido pela ANVISA, portanto, podemos concluir que chumbo e cadmio estão presentes nos batons, mas não podemos relatar um causalidade entre esta forma de exposição e os efeitos que as mesmas podem causar a saúde dos usuários desses produtos, devido a falta de trabalhos disponíveis na literatura.

\section{REFERÊNCIAS}

ATZ, V. L. Desenvolvimento de métodos para determinação de elementos traço em sombra para área dos olhos e batom. 2008. $75 \mathrm{f}$ Dissertação (Mestrado em Química) - Instituto de Química, Universidade Federal do Rio Grande do Sul, Porto Alegre.

AUGUSTO, A. D. S., FILHO, E. R. P. Determinação de $\mathrm{Cd}, \mathrm{Co}, \mathrm{Cr}, \mathrm{Cu}, \mathrm{Ni}$ e Pb em cosméticos infantis empregando técnicas espectroanalíticas. , 2014. 129 f. Dissertação (Mestrado em Química) Departamento de Química, Universidade Federal de São Carlos, São Carlos.

BATISTA, L. Determinação de chumbo em batons e tinturas capilares por espectrometria de absorção atômica. 2017. 43 f. Monografia (Licenciatura em Química) - Universidade Federal da Fronteira Sul - UFFS - Campus Serro Largo. Cerro Largo. 2017.

CHORILLI, M., SCARPA, M. V., LEONARDI, G. R., e FRANCO, Y. O. Toxicologia dos cosméticos. Latin American Journal of Pharmacy, v. 26, n. 1, p. 144, 2007.

FRAGA, M. V. B. de; ATZ, V.L. Desenvolvimento de metodologia para determinação de elementos traço em produtos cosméticos. Salão de Iniciação Científica. Livro de resumos. Porto Alegre: UFRGS. 2008.

GARCIA, R. Internacionalização comercial e produtiva na indústria de cosméticos: desafios competitivos para empresas brasileiras. Revista Produção, São Paulo, v. 15, n. 2, p. 158-171, Maio/Aug. 2005. https://doi.org/10.1590/S0103$\underline{65132005000200003}$

HIGUCHI, C. T. O uso racional de cosméticos e o seu descarte consciente e apelo do uso por produtos de origens orgânica e natural. Interfac EHS-Revista de Saúde, Meio Ambiente e Sustentabilidade, v. 8, n. 3, 2014.

MOREIRA, F. R.; MOREIRA, J. C. Os efeitos do chumbo sobre o organismo humano e seu significado para a saúde. Rev. Panam Salud Publica, v. 15, n. 2, p. 119-29, 2004. 
https://doi.org/10.1590/S1020-

$\underline{49892004000200007}$

SOARES, A. R. Desenvolvimento de métodos

para determinação de chumbo e níquel em

produtos cosméticos e cabelo por GF AAS. 2012.

$172 \mathrm{f}$. Tese (Doutorado em Química) - Instituto de

Ciências Exatas, Universidade Federal de Minas

Gerais, Belo Horizonte.

TREVIZAM, A. et al. Aplicação de Fósforo para

imobilização química do Cádmio em solo

contaminado. Química Nova, São Paulo, v. 33, n.

6, junho, 2010.

ZINI, J. et al. Estudo de metais e de substâncias

tóxicas em brinquedos. Química Nova, São Paulo,

v. 32, n. 4, março, 2009. 